\section{A tribute to Professor Shu Dong Xiao (1931-2016)}

Great sadness and deep affection marked the recent passing of Professor and Dr Shu Dong Xiao, a renowned and respected gastroenterologist, the emeritus director of Shanghai Institute of Digestive Disease and the emeritus professor of Renji Hospital, School of Medicine, Shanghai Jiao Tong University, who had dedicated his whole life to the academic and clinical study of digestive diseases. Professor Xiao died from cardiopulmonary failure on 22 July 2016 at the age of 85 .

Professor Xiao was born in 1931 in Huangpi city, Hubei Province, China. He graduated from the Shanghai Second Medical College (currently known as Shanghai Jiaotong University School of Medicine) in 1955, majoring in medicine. Because of his excellent performance he remained working as a resident of the Department of Internal Medicine in Hongren Hospital after graduation and later transferred to the Department of Internal Medicine of Renji Hospital. In 1978, he was promoted as the associate professor of Internal Medicine and in 1986 as the professor of Internal Medicine as well as the supervisor of postgraduate and $\mathrm{PhD}$ candidates. In 1984, Professor Xiao and Professor Shao Ji Jiang founded the first institute of digestive disease in China, the Shanghai Institute of Digestive Disease, where he established endoscopy as the main focus of diagnosing and treating GI diseases. Professor Xiao was a pioneer in several fields of GI disease including GI tumours and their precancerous lesions, and most notably Helicobacter pylori infection and its related diseases.

He served for many years as the President of the Chinese Society of Gastroenterology (CSGE), with outstanding accomplishment. In 2000, the CSGE joined the World Gastroenterology Organization and the Asian Pacific Association of Gastroenterology (APAGE), the two most authoritative academic organisations worldwide and in the Asia-Pacific region. Professor Xiao served as council member and later Director of APAGE in 2008. In July 2005, he became a Fellow of the Royal College of Physicians, London, UK. In November 2009, he was honoured as the Master of the World Gastroenterology Organization, who was heretofore the only laureate in China.
Professor Xiao was the chief editor of several influential textbooks of gastroenterology and internal medicine. He also served as an editorial board member of several excellent international journals including Gut, Alimentary Pharmacology \& Therapeutics, Best Practice \& Research in Clinical Gastroenterology, Journal of Gastroenterology and Hepatology, Journal of Gastroenterology, Scandinavian Journal of Gastroenterology, Hepatology and Gastroenterology and Gastrointestinal Endoscopy. With his vast experience as an author, reviewer and editor, he launched the Chinese Journal of Digestive Diseases, now known as the Journal of Digestive Diseases, and was its Editor in Chief till the end.

Professor Xiao understood that in order to make progress it was necessary to communicate and collaborate on a global scale. His charming personality, tireless enthusiasm and genuine love of gastroenterology enabled him to establish collaborations between China and many distinguished overseas institutions and researchers. Professor Xiao was also a superb teacher and an outstanding mentor to so many aspiring future leaders in gastroenterology, who benefited from his international connections and collaborations.

With Professor Xiao's death, the world has lost an outstanding scientist, a beloved clinician and an extraordinary leader, whose work was profound in the treatment of digestive diseases all over the world. He was indeed a pioneer and a grand master in the field of gastroenterology.

Professor Xiao is survived by his wife, Bao $\mathrm{Li} \mathrm{Lu}$, his son, Hong Xiao, daughter, Lu Xiao, and three grandchildren. He is deeply missed by his family, friends and colleagues both in China and around the world.

\section{Jing Yuan Fang}

Correspondence to Dr Jing Yuan Fang, Division of Gastroenterology and Hepatology, Department of Internal Medicine, Renji Hospital, School of Medicine, Shanghai Jiao Tong University, Shanghai Institute of Digestive Disease, 145 Middle Shandong Road, Shanghai 200001, China; jingyuanfang@sjtu.edu.cn

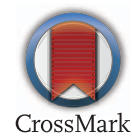

To cite Fang JY. Gut 2017;66:737.

Published Online First 24 February 2017

Gut 2017;66:737. doi:10.1136/gutjnl-2017-313951 